\title{
LA CRISIS DEL EURO. UNA REFLEXIÓN SOBRE LAS POLÍTICAS DE AUSTERIDAD Y EL DISEÑO INSTITUCIONAL DE LA UNIÓN ECONÓMICA Y MONETARIA EUROPEA
}

\section{THE EURO CRISIS. A REFLECTION ON AUSTERITY POLICIES AND THE INSTITUTIONAL DESIGN OF THE EUROPEAN ECONOMIC AND MONETARY UNION}

\author{
JAVIER OYARZUN \\ Departamento de Economía Aplicada I \\ Universidad Complutense de Madrid \\ joyarzun@ccee.ucm.es
}

Fecha de recepción: Enero 2015

Fecha de aceptación: Junio 2015

\section{RESUMEN}

La crisis del euro se ha analizado con profusión desde que, con el rescate a Grecia a principios de 2010, la Unión Económica y Monetaria (UEM) europea impuso unas políticas de austeridad muy severas a un conjunto de países periféricos. La singularidad de la respuesta de la UEM a la crisis se ha debido en buena parte a su diseño institucional y a la relación de fuerzas que han operado en la misma desde su nacimiento en 1992 y su puesta en marcha en el año 2000. En este artículo se analizan las causas de la adopción de esta política y se estudian los principales argumentos esgrimidos por los defensores e impulsores de la misma. La principal conclusión al respecto es que el diseño institucional de la UEM es profundamente asimétrico y que la política de austeridad aplicada ha beneficiado casi exclusivamente a los países acreedores y a determinados grupos económicos, siendo muy perjudicial para la mayoría de la población europea.

PALABRAS CLAVE: Unión Económica y Monetaria Europea (UEM), Política de austeridad, diseño institucional, fallo de mercado, países acreedores.

\begin{abstract}
The euro crisis has been analysed in depth since, with Greece's bailout in early 2010, the Economic and Monetary Union (EMU) imposed severe austerity policies to a set of peripheral countries. The uniqueness of the EMU response to the crisis was due, in a large measure, to its institutional design and the relationship of forces that have operated within, since its inception in 1992 and its start in 2000. This article analyses the causes of the adoption of this policy and studies the main arguments presented by its promoters. The main conclusion in this regard is that the institutional design of EMU is profoundly asymmetrical and the applied austerity policy has benefited almost exclusively the creditor countries and certain economic groups. This policy has proven to be very harmful to the majority of the European population.
\end{abstract}

KEYWORDS: Economic and Monetary Union (EMU), austerity policy, institutional design, market failure, creditor countries. 
Oyarzun, Javier. La crisis del euro. Una reflexión sobre las políticas de austeridad y el diseño institucional de la Unión Económica y Monetaria Europea.

JEL: E5, F3, F4, F5

\section{INTRODUCCIÓN}

La crisis del euro es un tema que se ha analizado con profusión desde que, con el rescate a Grecia a principios de 2010, la Unión Económica y Monetaria (UEM) europea impuso unas políticas de austeridad muy severas a un conjunto de países periféricos. Estas políticas han sido bastante diferentes de las aplicadas en otros países también afectados por la crisis, como EEUU, Reino Unido o Japón. La singularidad de la respuesta de la UEM a la crisis se ha debido, en cierta medida, a su diseño institucional y a la relación de fuerzas que han operado en la UEM desde su nacimiento en 1992. En este artículo se analizan las causas de la adopción de esta política y se estudian los principales argumentos esgrimidos por los defensores e impulsores de la misma. La principal conclusión al respecto es que el diseño institucional de la UEM es profundamente asimétrico y que la política de austeridad aplicada ha beneficiado casi exclusivamente a los países y grupos acreedores, siendo muy perjudicial para la mayoría de la población europea.

El artículo está dividido en siete apartados. En el siguiente apartado se esboza un relato de la historia de la política económica en el periodo de posguerra. Este relato sirve para enmarcar el momento histórico en que se produce la creación de la UEM, con la firma del tratado de Maastricht en 1992, y permite explicar algunas de las características del diseño de la unión monetaria. En el apartado tres se analizan los fallos de mercado del sistema financiero. Por un lado, por el papel central que ha tenido el sistema financiero como desencadenante de la crisis en EEUU y en la transmisión de la misma a la UEM; por otro, porque en las particularidades de la crisis en la zona euro, el sistema financiero ha sido uno de los principales protagonistas. El cuarto apartado aborda la creación de la UEM; se estudian los factores que influyeron en el diseño de la misma y se exponen las ventajas e inconvenientes que, en el momento de la firma del tratado de Maastricht, fueron expuestos por los analistas de la Comisión europea y otros economistas. En el apartado cinco, se exponen y analizan tres argumentos que han sido profusamente utilizados para justificar y defender las políticas de austeridad en la zona euro. En él tratamos de demostrar las falacias de esta argumentación. El apartado seis recoge algunas críticas que, desde nuestro punto de vista, merece el diseño institucional de la UEM, apuntando algunas modificaciones del mismo que mejorarían el funcionamiento de la UEM. Finalmente, en el apartado siete se presentan las conclusiones.

\section{CONTEXTO ECONÓMICO Y POLÍtICO EN QUE NACE EL EURO: ECONOMÍA Y POLÍTICA ECONÓMICA EN LA POSGUERRA}

En este apartado se expone un relato bastante difundido en las últimas décadas respecto a lo sucedido en la economía mundial desde el final de la Segunda Guerra Mundial. Este relato divide el periodo de posguerra en dos etapas: 1945-1973 y 1974-2015.

El éxito del periodo 1945-1973 -llamado "edad de oro del capitalismo"- se debe, en buena medida, al pacto social alcanzado entre sindicatos, patronal y gobiernos para practicar una política de aumento salarial relacionado con el aumento de la 
Oyarzun, Javier. La crisis del euro. Una reflexión sobre las políticas de austeridad y el diseño institucional de la Unión Económica y Monetaria Europea.

productividad a cambio de inversión por parte de las empresas y una política económica keynesiana de carácter redistributivo y anticíclico por parte de los gobiernos. El éxito se expresa en un gran aumento de la productividad y del PIB p/c, durante todo este periodo (en los países desarrollados pero también en los países en desarrollo), así como en el establecimiento de un Estado del bienestar en la mayoría de los países desarrollados. En esta fase, las transacciones internacionales se encuentran reguladas: el movimiento de capitales está sometido a control de cambios y el comercio internacional se va liberalizando de forma muy gradual. También conviene señalar que, en esta etapa histórica, el temor al contagio del comunismo influyó poderosamente en la adopción de un sistema de economía social de mercado, con una fuerte intervención del Estado para impulsar el crecimiento y redistribuir la renta.

La crisis de 1973 (y 1979) y el abandono del sistema de tipos de cambio fijos ponen en cuestión el paradigma anterior, al producirse estanflación (inflación y paro simultáneamente), e irrumpen nuevas teorías de signo ultraliberal y conservador (monetarismo de Friedman, expectativas racionales de Lucas, economía de la oferta de Laffer) que van a imponerse en los años 80 . Las recomendaciones de política económica que se derivan de dichas teorías pueden resumirse en el denominado "consenso de Washington": liberalización interna y externa, mayor desregulación de la economía, privatización de las empresas públicas, reducción de impuestos, libertad de movimientos de capital, corrección de los desequilibrios macroeconómicos: baja inflación, reducción del déficit presupuestario y de la balanza por cuenta corriente.

Como consecuencia del triunfo de la nueva corriente de pensamiento y de la política propuesta por estos teóricos, se aceleran las reformas indicadas en el párrafo anterior. Esta nueva política económica permite un crecimiento más moderado que en la fase anterior pero logra estabilidad de precios y mayor control de las finanzas públicas, lo que los historiadores, siguiendo la observación de Bernanke, han llamado "Edad de la gran moderación". Otras consecuencias son, en los países de la OCDE: un aumento de la desigualdad de las rentas, un crecimiento bajo del salario real y la escalada del endeudamiento de las familias (Vilariño, 2011b).

En el plano internacional, la liberalización de los movimientos de capital -que se generaliza a nivel mundial a partir de los años 1990- genera crisis financieras profundas (UE 1992-94, México 1994, Sudeste asiático 1998). Las recetas del Consenso de Washington, impuestas a los países que solicitan financiación al FMI o al Banco Mundial -desde los años 1980- producen largas fases de estancamiento, en África y América Latina.

La aceleración de la globalización ha generado una asimetría profunda en el reparto del poder a nivel mundial: el poder de los grupos económicos (empresas multinacionales y grandes bancos) aumenta mientras el poder político queda mermado. Se produce un fallo institucional a nivel global. La creciente liberalización mundial no va asociada a una regulación internacional del nuevo sistema mundial de relaciones económicas.

Los Organismos Económicos Internacionales, controlados por los países desarrollados, sostienen y aplican las políticas del consenso de Washington. 
Oyarzun, Javier. La crisis del euro. Una reflexión sobre las políticas de austeridad y el diseño institucional de la Unión Económica y Monetaria Europea.

Por su parte, las empresas internacionalizadas pueden operar con gran libertad en casi todo el mundo, con escaso control por parte de las Administraciones. Ello les permite minimizar el pago de impuestos a través de la manipulación de los precios de transferencia ${ }^{1}$, la ingeniería fiscal, la constitución de lobbys y el establecimiento de la residencia de sociedades del grupo empresarial en paraísos fiscales.

Esta rápida globalización de corte neoliberal ha generado profundos fallos de mercado, esto es situaciones en las que el mercado no funciona de manera eficiente. También se han producido fallos de Estado, aquellos que tienen lugar cuando las instituciones del Estado -0 las instituciones supranacionales- no funcionan de manera eficiente.

\section{LOS FALLOS DE MERCADO DEL SISTEMA FINANCIERO}

La desregulación en un contexto de globalización amplifica los fallos de mercado del sistema financiero. La aceleración del proceso de desregulación financiera se produce en 1999 cuando el gobierno de Bill Clinton decide derogar la ley GlassSteagall, aprobada en 1933 por el gobierno de Roosevelt ${ }^{2}$. Estos fallos, que son la causa fundamental de la crisis actual, son los siguientes:

a) Las economías de escala son muy acusadas en el sistema financiero lo que propicia la fusión de los bancos, que alcanzan enormes dimensiones. El aumento de la concentración en el sistema financiero aumenta el riesgo sistémico. El peligro que entraña esa dimensión es que algunos bancos se vuelven demasiado grandes para quebrar. Este hecho tiene dos efectos muy negativos. Por un lado, al ser los bancos conscientes de que en caso de quiebra serán rescatados por el Estado, se produce un incentivo a asumir riesgos excesivos (riesgo moral); por otro, el Estado se ve obligado a rescatarlos, lo que implica una transferencia de renta de la sociedad al sistema financiero.

b) La información asimétrica (el comprador de un producto financiero sabe menos sobre el mismo que el vendedor) se ha extendido y ha aumentado con la desregulación. La titulización de las hipotecas "subprime", convirtiendo las hipotecas en un título financiero opaco, es un claro ejemplo de este tipo de fallo de mercado.

c) El conflicto de intereses en las agencias de calificación de riesgo (cobran por evaluar y por asesorar) es otro fallo de mercado del sistema financiero. El incentivo a correlacionar el ingreso por el asesoramiento con la calificación otorgada es muy elevado. Hay que recordar que Lehman Brothers tenía una calificación triple A unos días antes de su quiebra.

d) El sistema bancario, por su propia naturaleza, propicia en los agentes económicos una conducta que pone en peligro el funcionamiento de la economía; cuando los depositantes sospechan que un banco no tiene liquidez puede producirse un pánico bancario y el banco quebrar aunque sea solvente.

\footnotetext{
${ }^{1}$ Como las EMN tienen filiales en varios países, cuando se realizan transacciones entre filiales pueden aplicar precios menores a las mercancías y servicios que son objeto de dichas transacciones con el fin de reducir el pago de aranceles e IVA que les correspondería.

${ }^{2}$ Esta ley diferenciaba claramente entre los bancos comerciales y los bancos de inversión. Estos últimos no podían captar depósitos de particulares. La ley permitía a la Reserva Federal ejercer un fuerte control de la especulación. Finalmente la ley Glass-Steagall instauró el sistema del fondo de garantía de depósitos, que reduciría considerablemente los pánicos bancarios.
} 
Oyarzun, Javier. La crisis del euro. Una reflexión sobre las políticas de austeridad y el diseño institucional de la Unión Económica y Monetaria Europea.

e) Los mercados de deuda muestran grandes imperfecciones. Los agentes toman como referencia de "default" indicadores, como la prima de riesgo de los bonos, cuando este dato no proporciona suficiente información sobre el riesgo de impago (Vilariño et al. 2011a).

f) El sistema financiero facilita la formación de burbujas en activos reales (sector inmobiliario) o financieros (acciones). La propia burbuja crediticia es condición necesaria para las burbujas tanto inmobiliaria como bursátil (Kindleberger, Aliber, 2011). Las burbujas constituyen un fallo de mercado pues generan equilibrios, además de inestables ${ }^{3}$, malos (De Grauwe, 2012) al conducir a situaciones de crisis (cuando pincha la burbuja).

En definitiva, el sistema financiero es el más sensible del sistema económico y requiere de una regulación profunda y eficiente. La afirmación de que el sector financiero debe auto-regularse ha sido uno de los mayores errores de la ideología neoliberal.

\section{LA CREACIÓN DE LA UNIÓN ECONÓMICA Y MONETARIA. VENTAJAS E INCONVENIENTES.}

El objetivo de lograr una estabilidad cambiaria en la Unión Europea 4 (UE) ha sido permanente desde su fundación en 1957. Cuando el sistema de Bretton Woods naufraga en 1971, la UE establece un sistema de tipos fijos entre las monedas que se denominó "serpiente monetaria". Este sistema fracasó pero, rápidamente, en 1979, se creó el Sistema Monetario Europeo (SME), que estaría vigente hasta la adopción del euro en $1999^{5}$ y sigue en vigor para los países de la UE que aún no han entrado en el euro y deben hacerlo ${ }^{6}$.

\footnotetext{
${ }^{3}$ Cuando el aumento del precio de un activo propicia un aumento de su demanda (lo que sucede con las burbujas) el equilibrio es inestable. Para que el equilibrio sea estable, el aumento del precio debe ir acompañado de una reducción de la demanda.

${ }^{4}$ La denominación UE se establece con el Tratado de Maastricht de 1992. Hasta esa fecha, la UE se llamaba Comunidad Económica Europea (CEE).

${ }^{5}$ Cuando el sistema de Bretton Woods empezó a ser cuestionado (a finales de los 60), la CEE puso en marcha el Plan Werner (1969), que preveía la constitución de una UEM a lo largo de la década de los 70. El plan señalaba los requisitos para alcanzar este objetivo: a) libertad de circulación de capitales; b) fijación de los tipos de cambio; c) política monetaria común; d) fortalecer la coordinación de las políticas fiscales de los países miembros. El Plan Werner fue aprobado por el ECOFIN en 1971; sin embargo, el plan era prematuro en ausencia de un mercado único y la posterior falta de voluntad política para llevarlo adelante hizo que naufragara. Se optó entonces por implantar el sistema conocido como "serpiente monetaria", un sistema de tipos cuasi fijos menos ambicioso que el plan Werner, que también naufragó tras sucesivas salidas y devaluaciones de varias monedas. Finalmente, en 1979, entró en vigor el Sistema Monetario Europeo (SME) que ha estado vigente hasta hoy. El SME era un sistema muy similar al de Bretton Woods (BW), con algunas diferencias. En primer lugar, no había ninguna moneda ligada al oro (lo estaba el \$ en BW). La moneda que servía de referencia para fijar las paridades era una moneda cesta, el ECU. En segundo lugar, había dos bandas de fluctuación, más anchas que la única que había en BW (1\%): del 2.25\% y del 6\%. Cada país integrado en el sistema podía optar por cualquiera de las dos. En tercer lugar, los cambios de paridad (devaluación o revaluación) no se permitían de forma automática sino que requerían la aprobación del Comité de Gobernadores de los Bancos Centrales de los países miembros del sistema, donde se negociaba el grado de la variación de la paridad solicitada por un país.

La evolución del SME puede considerarse, en líneas generales, satisfactoria. En los años 80, hasta 1987, se produjeron varios reajustes de los tipos de cambio; entre 1987 y 1992, la estabilidad fue absoluta: ninguna moneda alteró su paridad. Más tarde, en 1992 y 1993, se produjeron las llamadas tormentas monetarias que cuestionaron seriamente la viabilidad del sistema, que, a pesar de ello, subsistió con una gran estabilidad desde que, en 1993, se ampliaron las bandas al 15\% (banda única para todas las monedas). El SME cumplió, según el Consejo Europeo, con su principal objetivo: favorecer la coordinación y una mayor disciplina de las políticas
} 
Oyarzun, Javier. La crisis del euro. Una reflexión sobre las políticas de austeridad y el diseño institucional de la Unión Económica y Monetaria Europea.

La decisión de crear el euro se fue fraguando tras la firma del Acta Única Europea (AUE), en 1986. El AUE es uno de los principales tratados de la UE; por él se crea el mercado único europeo, un programa muy ambicioso de integración que culmina en 1992, el mismo año de la firma del Tratado de Maastricht. El AUE implica las llamadas cuatro libertades básicas en el espacio económico de la UE: circulación de mercancías, prestación de servicios, movilidad de personas y trabajadores y circulación del capital. Las tres primeras libertades afectaron al espacio económico de la UE pero la cuarta se decidió mundializarla, en sintonía con el auge del pensamiento neoliberal que iba ganando influencia en esos años.

El presidente de la Comisión Europea en ese periodo, el francés Jacques Delors, convocó, a partir de 1989, varias conferencias preparatorias para elaborar el acuerdo que desembocaría en el Tratado de Maastricht. En dichas conferencias se pudieron observar las posiciones de los países de la UE, doce en ese momento. Entre las mismas, cabe destacar la de Alemania frente a los demás países. En primer lugar, Alemania se encontraba muy cómoda en el Sistema Monetario Europeo, pues la moneda de Alemania, el marco, se había constituido en la moneda ancla del sistema y ello otorgaba a este país una ventaja considerable sobre el resto de países: como EEUU en el sistema de Bretton Woods, Alemania era el único país del SME que podía realizar una política monetaria independiente. Esta ventaja facilitó, por ejemplo, el programa de reunificación con Alemania del este pues pudo subir los tipos de interés, sin que el marco se apreciara, para frenar el aumento de la inflación. Fueron los demás países quienes se vieron forzados a aumentar los tipos de interés para evitar la depreciación de sus monedas ${ }^{7}$. En segundo lugar, y como consecuencia de lo recién señalado, Alemania no estaba interesada en la creación de la moneda única. Es cierto que el gobierno alemán de Helmut Kölh se mostraba agradecido con el resto de los países de la UE y, de manera muy particular con Francia, por no haber puesto obstáculos a la reunificación de Alemania. Por ello, seguramente, se mostró dispuesta a aceptar el proyecto de la moneda única. Sin embargo, su posición dominante en la economía de la UE le permitió plantear unas exigencias muy severas para aceptar abandonar el marco y entrar en el euro. Estas exigencias pueden resumirse en los llamados "criterios de convergencia" del Tratado de Maastricht ${ }^{8}$. Dichos criterios eran las condiciones macroeconómicas que debía cumplir un país de la UE para acceder al euro ${ }^{9}$.En tercer lugar, Alemania

monetarias. Al estar presentes en el SME varias monedas fuertes (con baja inflación), en particular el marco alemán, los demás países se vieron forzados a controlar más su propia inflación para evitar tener que recurrir a la devaluación como vía de ajuste a su pérdida de competitividad frente a los mercados menos inflacionistas.

${ }^{6}$ En la UE están exentos de la obligación de adoptar el euro algunos países que lograron ese privilegio, llamado cláusula de "opting out", en la década de los 90'. Esos países son Gran Bretaña, Dinamarca y, de alguna manera, Suecia. Los países que se incorporaron a la UE en el siglo XXI sí tienen la obligación de adoptar el euro y, para ello, deben pertenecer al SME.

${ }^{7}$ El aumento de la inflación en Alemania se debió a la decisión de convertir los marcos de Alemania del Este en marcos de Alemania del oeste a la paridad 1 por 1. Como el poder adquisitivo de los marcos del este era mucho menor que el de los marcos del oeste, el efecto que tuvo esa decisión política fue aumentar súbitamente el poder adquisitivo de los alemanes del este y aumentar, por lo tanto, la demanda de productos de Alemania del oeste, mucha más desarrollada que la del este. Este incremento de la demanda provocó un aumento de la inflación.

${ }^{8}$ También en el diseño institucional de la UEM, que trataremos con más detalle en el apartado 6.

${ }^{9}$ Se establecieron cuatro criterios de convergencia, uno de ellos, el segundo, con dos requisitos: 1) relativo a la estabilidad de precios: la tasa de inflación en 1998 de un país candidato no podrá exceder en 1.5 puntos porcentuales a la media de la registrada en los tres Estados miembros con menor tasa de inflación. 2) Relativo a la situación del presupuesto público: en 1998, el déficit público de un Estado candidato debe ser inferior al 3\% del PIB y su deuda pública inferior al $60 \%$ del PIB. Este criterio tenía cierta flexibilidad. 3) Relativo a la

Papeles de Europa 
Oyarzun, Javier. La crisis del euro. Una reflexión sobre las políticas de austeridad y el diseño institucional de la Unión Económica y Monetaria Europea.

consideraba que las características de los países de la UE diferían considerablemente. Un conjunto de países, los más desarrollados, tenían economías más eficientes y productivas y más estables en términos macroeconómicos (menor inflación, tipos de interés, déficit público). Alemania consideraba que este tipo de países podían cumplir en un breve plazo los criterios de convergencia. Los países periféricos, en cambio, eran mucho más inestables y debían hacer numerosas reformas y esfuerzos de ajuste para llegar a cumplir los criterios. Por ello, Alemania propuso reiteradamente que se formaran dos grupos de países para constituir la UEM. Un primer grupo, con Alemania y Francia a la cabeza, constituirían la UEM inicial, en un par de años. Un segundo grupo entraría más tarde en una UEM ya constituida. Esta posición vino a denominarse la "Europa de dos velocidades" y fue rechazada categóricamente por los países periféricos. Estos consideraban que las dos velocidades consagraban países de primera y segunda categoría, lo cual era un signo inadmisible de insolidaridad en la UE. Finalmente, Alemania cedió en este punto y se estableció que en 1999 la Comisión realizaría el examen de los criterios de convergencia a los países candidatos a entrar en la UEM.

Otro aspecto central del programa exigido por Alemania para participar en la moneda común fue el diseño del Banco Central Europeo (BCE). El BCE debía ser como el Banco Central alemán (Bundesbank): ser totalmente independiente de los poderes políticos y tener como único objetivo un control férreo de la inflación ${ }^{10}$. Además, el BCE no podía comprar deuda pública de los Estados miembros de la UEM en el mercado primario.

En 1992 se firma de Tratado de Maastricht por el que se crea la Unión Económica y Monetaria (UEM). El Tratado se enmarca en el cambio de modelo económico señalado en el primer apartado. Introduce una moneda única en un mercado que ha sido casi totalmente liberalizado ese año por la aplicación del Acta Única Europea. En un documento elaborado por la UE (Commission des Communautés européennes, 1990) se señalan las ventajas e inconvenientes de la adopción del euro. En lo que sigue, emplearemos en buena medida los argumentos de este documento.

\subsection{Ventajas}

- Ganancias debidas a la eliminación de los costes de transacción. Este efecto es, junto a la eliminación del riesgo de cambio, el más claro de los efectos positivos de la adopción del euro. Los costes de transacción tienen dos componentes que pueden medirse, en primer lugar, mediante lo que le cuesta a la banca -en términos de salarios- la realización de las operaciones. En segundo lugar, a través del beneficio que obtiene la banca por este negocio ${ }^{11}$. El estudio de la Comisión

convergencia de los tipos de interés: el tipo de interés promedio nominal a largo plazo en 1998 no debe exceder en más de 2 puntos porcentuales el de los tres países con menor inflación. 4) Relativo a la participación en el Mecanismo de Tipo de Cambio del SME: no haber devaluado ni haber sufrido tensiones graves durante, al menos, dos años antes del examen, en los márgenes normales de fluctuación del SME (banda del 2.25\%).

${ }^{10}$ Según un relato muy extendido, los alemanes tienen aversión a la inflación desde que tras la $1^{\text {a }}$ Guerra Mundial, al inicio de los años veinte, se produjera una hiperinflación que desestabilizó mucho al país tanto económica como políticamente.

${ }^{11}$ Normalmente, el coste de las operaciones se asocia a la comisión que cobra el banco por cada operación, en tanto que el beneficio del banco proviene del diferencial entre el tipo comprador y el tipo vendedor para cada 
Oyarzun, Javier. La crisis del euro. Una reflexión sobre las políticas de austeridad y el diseño institucional de la Unión Económica y Monetaria Europea.

señaló que este efecto supondría, con una estimación prudente, un ahorro anual permanente del $0.5 \%$ PIB de la UEM.

- Ganancias debidas a la eliminación de los costes derivados de la existencia de riesgo cambiario ${ }^{12}$. Numerosos agentes económicos contratan alguna modalidad de seguro de cambio, como un tipo de cambio a plazo, un contrato a futuros o una opción para evitar ese riesgo. El documento de la Comisión estima en un $0.2 \%$ del PIB el ahorro derivado de este efecto de la moneda única.

- Ganancias por convertirse el euro en medio de pago y moneda de reserva internacional. Aunque son difíciles de estimar, son ambas muy importantes. La conversión del euro en un medio de pago internacional supone un ahorro considerable: en la medida en que las operaciones comerciales con países de fuera del área euro se facturen en euros, tanto los costes de transacción como los costes del seguro de cambio se traspasan al agente del país de fuera del área euro. La conversión del euro en moneda de reserva internacional implica que los agentes económicos del resto del mundo, públicos y privados, consideran que el euro es una moneda sólida y quieren mantener activos denominados en dicha moneda. El caso de la moneda de EEUU muestra la principal ventaja que aporta a este país el status del dólar como primera moneda de reserva del mundo. Los bancos centrales de todo el mundo y muchos agentes privados invierten en deuda pública de EEUU -pese a su baja rentabilidad nominal- o colocan sus ahorros en activos situados en EEUU porque el dólar es la moneda de la primera potencia del mundo y su economía sigue siendo considerada sólida y fiable. Esta característica ha permitido a EEUU obtener, desde 1970, financiación internacional a un coste muy reducido ${ }^{13}$.

- Otra ventaja esgrimida por una mayoría de los analistas favorables a la creación de la UEM, era el aumento de la competencia que se lograría con el mercado único ya creado. La mayor competencia y la total libertad de los movimientos de capital alcanzada en 1992, mejorarían notablemente la asignación de recursos y, en consecuencia, asegurarían una mayor productividad y crecimiento.

- En el marco macroeconómico, se citaban dos efectos muy positivos de la UEM. Por un lado, la estabilidad de los precios. Dado que la política monetaria del BCE iba a tener como único mandato la estabilidad de precios, el severo control que ejercería el BCE a partir de la independencia que le otorgaba el Tratado de Maastricht generaba unas expectativas de muy baja inflación en el área euro. A

moneda. Naturalmente, el beneficio del banco es un coste para sus clientes. Es interesante indicar que en el periodo posterior a la firma del Tratado de Maastricht los bancos de la futura UEM presionaron a la Comisión y el Consejo Europeos para que los bancos fueran de alguna forma compensados por la pérdida del importante negocio de intermediación en el mercado de divisas europeo. Sin embargo, que se sepa no hubo compensación económica.

${ }^{12}$ El riesgo cambiario es el coste que puede representar para un agente económico la modificación del tipo de cambio entre la moneda en la que opera habitualmente (la de su país de residencia) y la de otro país cuando dicho agente tiene una posición activa o pasiva en esta última moneda. Si el agente tiene un posición activa (es decir un saldo acreedor en moneda extranjera), el riesgo cambiario consiste en que dicha moneda se deprecie o devalúe porque en tal caso su capital o patrimonio se reduce en términos de moneda nacional. Por el contrario si el agente tiene una posición pasiva (es decir un saldo deudor en moneda extranjera), el riesgo cambiario surge si la moneda extranjera se aprecia porque ello aumentará su deuda en términos de moneda nacional.

${ }^{13}$ Una tercera ventaja ligada al papel del euro como moneda internacional deriva de las denominadas ganancias de señoreaje. Es decir, el hecho de que los billetes y monedas en euros sean empleados en otros lugares del mundo, algo que no ha ocurrido todavía de forma significativa. En ese caso, el Banco Central Europeo podría obtener ganancias de los activos que obtiene a cambio del dinero en efectivo emitido, que no genera ninguna rentabilidad a su tenedor. 
Oyarzun, Javier. La crisis del euro. Una reflexión sobre las políticas de austeridad y el diseño institucional de la Unión Económica y Monetaria Europea.

las ventajas conocidas de la baja inflación (estabilidad, previsibilidad, seguridad) se sumaba la expectativa de un bajo tipo de interés nominal (y real), un resultado especialmente positivo para países que, como España, habían tenido tradicionalmente tipos de interés nominales muy elevados. Sin embargo, el peligro que acechaba tras una brusca bajada del tipo de interés no fue percibido por los analistas españoles.

\subsection{Inconvenientes}

Los inconvenientes del euro fueron estudiados igualmente por la Comisión. Estuvieron centrados en tres aspectos. En primer lugar, en la pérdida de los instrumentos de ajuste de la política monetaria debida a la transferencia de esta última a la UEM. En segundo lugar en la aplicación a la UEM de la teoría de las uniones monetarias óptimas enunciada por Robert Mundell en 1961. En tercer lugar, también se planteó la idoneidad de una unión monetaria sin unión fiscal.

- Con el euro, los países de la UEM pierden el control sobre el tipo de cambio y el tipo de interés, que son dos instrumentos de ajuste fundamentales de la política monetaria. Son instrumentos con efecto sobre el crecimiento, la inflación, el empleo y los equilibrios internos y externos de una economía. Su pérdida es fundamental como veremos más tarde. De momento cabe señalar que la Comisión y la mayoría de los analistas de la época redujeron significativamente la importancia de la pérdida de los mismos.

Por un lado, se señaló que la pérdida del tipo de cambio no era muy relevante teniendo en cuenta que los países sustituían un sistema de tipos fijos por una moneda común; en ambos casos, la política monetaria era poco operativa; más aún, como en el SME la moneda ancla era el marco alemán (que mantenía una notable autonomía en política monetaria), la adopción del euro daría alguna competencia a los países del euro sobre esta moneda (al pertenecer al Consejo del BCE) y, por otro lado, restaría autonomía monetaria a Alemania (que perdía la soberanía que antes tenía sobre el marco). Finalmente, a la pérdida de la posibilidad de devaluar para recuperar la competitividad en caso de fuertes desequilibrios de la cuenta corriente, no se le atribuyó tampoco excesiva importancia. Se pensó que, al ser la política monetaria común, los diferenciales de inflación prácticamente desaparecerían y, por lo tanto, la necesidad de devaluar. Este fue, sin duda, uno de los mayores errores de predicción de los analistas de la época. Como veremos, la devaluación del tipo de cambio o devaluación externa tiene unos costes sociales y económicos mucho menores que la llamada "devaluación interna".

- Por lo que respecta a la pérdida de influencia sobre la fijación del tipo de interés, las objeciones aún fueron menores; en particular en países con una política monetaria más laxa, como España, se decía que cambiábamos una moneda mala -la peseta- por una buena -el euro-. La moneda buena sería menos inflacionista, dados los duros criterios de convergencia y la exigencia al BCE de mantener la inflación en torno al $2 \%$; en consecuencia, los tipos de interés deberían ser también menores. Este análisis fue acertado pero de alcance limitado pues no se tuvo en cuenta los efectos que, en un país como España por ejemplo, una caída brusca de los tipos de interés podía tener sobre la demanda agregada de activos inmobiliarios y financieros. En definitiva, no se advirtió la posibilidad, como así sucedió, de la aparición de las burbujas inmobiliaria y bursátil alimentadas por una 
Oyarzun, Javier. La crisis del euro. Una reflexión sobre las políticas de austeridad y el diseño institucional de la Unión Económica y Monetaria Europea.

burbuja de crédito. Esta última financiada, en buena medida, por los superávit por cuenta corriente de Alemania desde la creación del euro.

- La aplicación de la teoría de las áreas monetarias óptimas (Mundell, 1961; De Grauwe, 1992) dio resultados que no eran excesivamente positivos. Las dos características principales que debían reunir los países de un área monetaria para que esta pudiera ser catalogada como óptima no parecían cumplirse en la mayoría de los países del área euro. Esas características eran, de un lado, una gran flexibilidad de los precios de bienes, servicios y factores; de otro una alta movilidad geográfica del factor trabajo. El análisis de Mundell parte del análisis de la respuesta que deben tener los países que pasan a formar una unión monetaria ante lo que denomina "shocks asimétricos". El shock se supone exógeno y puede ser de oferta o demanda. Por ejemplo, un shock de oferta sería el alza del precio del petróleo y uno de demanda sería la desviación de la demanda interna o externa de un país hacia otro país por diferenciales de inflación. El hecho de que sea asimétrico significa que el impacto de su efecto es de distinta intensidad en los países del área monetaria. En tales casos, Mundell establece que el efecto de un shock asimétrico se minimizará en los países más afectados por el mismo cuanto: a) mayor sea la movilidad geográfica laboral de un país, y b) mayor sea la flexibilidad de los precios (los salarios, sobre todo). Una alta movilidad geográfica daría lugar a una fuerte emigración laboral en el país donde la intensidad del shock asimétrico ha sido mayor; esos emigrantes tendrían acogida en los países donde el shock ha tenido un impacto nulo, reducido o de signo opuesto. En cuanto a la flexibilidad de los salarios, permitiría que una reducción de los mismos, en el caso de una fuerte asimetría en el aumento de la inflación, pudiera restablecer la competitividad en el país y, en consecuencia, aumentar la demanda externa y el nivel de empleo. Este argumento, como veremos más adelante, se convertirá en uno de los principales empleados para defender la política de austeridad en la zona euro.

La mayoría de los análisis sobre el cumplimiento en los países de la UE de las dos características señaladas por la teoría de las áreas monetarias óptimas señalaban que el nivel de movilidad geográfica en el mercado laboral era bastante bajo, sobre todo en la movilidad internacional. Motivos culturales y lingüísticos frenaban mucho la movilidad geográfica: el número de trabajadores de otros países de la UE era muy bajo en casi todos los países europeos. En cuanto a la segunda característica -la flexibilidad salarial-, se señalaba que también era muy baja debida al predominio, sobre todo en los países periféricos, de legislaciones laborales muy favorables a los trabajadores. Sin embargo, muchos autores, a principios de los noventa, se mostraban contrarios a esta argumentación. Señalaban que la convergencia entre los países de la UE había reducido las diferencias económicas por lo que la probabilidad de shocks asimétricos también se había reducido.

- Finalmente, algunos analistas consideraron que el alcance económico de la UEM acordada en Maastricht era desequilibrado: una unión monetaria sin unión fiscal podía crear graves problemas. En particular, muchos economistas de EEUU señalaron que el diseño institucional de la UEM era deficiente. Al comparar el modelo de la UEM con la economía de EEUU aparecía que la posibilidad de una corrección de los desequilibrios a través de un presupuesto federal era imposible. El presupuesto de la UE es mínimo (1.1\% del PIB). En EEUU y cualquier país desarrollado hay mecanismos de redistribución vía presupuestaria para las regiones que experimentan crisis. Nada de eso existe en el diseño de la UEM. 
Oyarzun, Javier. La crisis del euro. Una reflexión sobre las políticas de austeridad y el diseño institucional de la Unión Económica y Monetaria Europea.

Esta crítica, formulada sobre todo desde EEUU fue rechazada por varios economistas europeos con el argumento de que, en realidad, los economistas de EEUU querían defender la situación de privilegio de que gozaba el dólar como medio de pago y activo de reserva internacional y no querían la aparición de un competidor, el euro, en la escena internacional. Los hechos, como ahora sabemos, han dado la razón al argumento de varios economistas de EEUU.

\section{LA POLÍTICA DE AUSTERIDAD Y SUS ARGUMENTOS}

La política de austeridad se inicia, en la UEM, en mayo de 2010, coincidiendo con el primer rescate de Grecia. En la reunión del eurogrupo celebrada en esa fecha se establecen las políticas que, a partir de ese momento, deben aplicarse en todos los países de la zona euro y son mucho más drásticas en los países con mayores desequilibrios en términos de déficit público.

La política de austeridad, que ha implicado una reducción muy intensa del gasto público y de los salarios, tiene como efecto una fuerte disminución de la demanda agregada. Sin demanda, la actividad económica se reduce y la economía entra en recesión. La mayoría de los historiadores económicos señalan que la política de austeridad ha impedido o retrasado considerablemente la salida de la crisis a lo largo de la historia. En 2012 varios países de la UEM entraron en recesión y en 2013, aunque la situación ha sido algo mejor en el conjunto del área, varios países han registrado estancamiento y otros, como España, han seguido en recesión. En 2014, sigue la atonía - muy bajo crecimiento- y planea el fantasma de la deflación; el BCE, por medio de Draghi, ha señalado que hará lo necesario para evitar la deflación (inyección de liquidez y compra de bonos públicos en el mercado secundario). En 2015 se ha iniciado el programa de inyección de liquidez (quantitative easing), centrado en la compra de bonos de los tesoros de los países de la UEM (excluyendo a Grecia) en el mercado secundario. La economía en muchos países de la zona está experimentando una mejoría ${ }^{14}$.

Hay varios argumentos en defensa de la política de austeridad, mantenidos por quienes la han impuesto en la UEM, Alemania y la troika, fundamentalmente. Estos argumentos son repetidos por los gobiernos que se ven forzados a aplicar las medidas de austeridad en sus países. Son los siguientes: a) la política de austeridad es un mal necesario para una recuperación "sana" cuando los países han vivido por encima de sus posibilidades, incurriendo en déficit público y aumentando la deuda hasta niveles excesivos. b) Los desequilibrios macroeconómicos señalados (excesivos déficit público y deuda pública y privada) "inquietan" a los mercados; la desconfianza de estos últimos se transmite a la prima de riesgo de las nuevas emisiones de deuda, lo que impide la recuperación de las economías "castigadas" por el encarecimiento de la deuda. c) Las reformas estructurales asociadas a la política de austeridad permiten aumentar la competitividad internacional de los países en crisis a través de la reducción de salarios y precios. La mayor competitividad lograda por esta vía (que equivale a una devaluación del tipo de cambio) permitirá aumentar las exportaciones y reducir las importaciones, con lo que dará un impulso a la demanda externa e interna.

\footnotetext{
${ }^{14}$ En buena medida, por la masiva inyección de liquidez, por la depreciación del euro, por la reducción del precio del petróleo y por la relajación del programa de reducción del déficit público.
} 
Oyarzun, Javier. La crisis del euro. Una reflexión sobre las políticas de austeridad y el diseño institucional de la Unión Económica y Monetaria Europea.

A continuación analizaremos cada uno de estos tres argumentos, centrando la atención en el caso de España.

a) La política de austeridad es un mal necesario para una recuperación "sana" cuando los países han vivido por encima de sus posibilidades, incurriendo en déficit público y aumentando la deuda hasta niveles excesivos.

La afirmación "vivir por encima de sus posibilidades" es ambigua cuando se refiere a la economía de un país. Obviamente, se quiere decir que el endeudamiento del conjunto del país ha sido excesivo. Sin embargo, es preciso matizar, distinguiendo entre el sector público y el privado. En el caso de Grecia, ambos endeudamientos habían sido excesivos pero el del sector público había sido ocultado con "ingeniería contable". En el caso de España, el sector público tenía una de las deudas menores de la UEM (menor al 40\% del PIB, en 2008) mientras que el sector privado sí que estaba muy endeudado. Además, España tenía superávit fiscal en 2008. En consecuencia, en el caso español, como en el de Irlanda, la afirmación correcta sería: "el sector privado ha vivido por encima de sus posibilidades".

El endeudamiento en sí no es negativo; permite vivir mejor o emprender actividades porque se aplaza hacia el futuro el pago del consumo o la inversión presente. El problema surge cuando el endeudamiento es excesivo. En ese caso, para evitar que se vuelva impagable hay que refinanciar y reestructurar la deuda, lo que traslada hacia el futuro la devolución de la misma. Esto significa trasladar la deuda a las siguientes generaciones. Sin embargo, aunque ciertamente una parte del endeudamiento no ha financiado un aumento de la capacidad productiva, el resto sí lo ha hecho y las nuevas generaciones también heredan esas nuevas inversiones.

En el caso de España, como se ha señalado, el sector público no estaba muy endeudado y, además, tenía superávit fiscal en el momento de la crisis. Sin embargo, por un lado la crisis ha puesto en funcionamiento los estabilizadores macroeconómicos automáticos (seguro de desempleo, reducción de la carga fiscal) lo que ha conducido a un fuerte aumento del gasto público; por otro, se ha producido una socialización parcial de la deuda privada (rescates bancarios). Ambos fenómenos han aumentado el déficit público que se ha financiado con nueva deuda. La deuda pública en España se acerca en la actualidad al 100\% del PIB.

Si se acepta que hay que reducir el déficit, la cuestión está en cómo y cuándo se debe lograr ese objetivo. Se puede reducir el déficit aumentando los ingresos, reduciendo los gastos o haciendo ambas cosas a la vez. En el caso español, el aumento de los ingresos se ha intentado con la subida del IVA y del IRPF sobre las rentas del trabajo. El impuesto de sociedades no se ha modificado y tiene un tipo efectivo extremadamente bajo para las grandes empresas ${ }^{15}$. Los técnicos de Hacienda consideran que el $70 \%$ del fraude fiscal en España lo realizan las grandes fortunas, los grandes bancos y las grandes empresas. Sin embargo, no solo no ha aumentado la lucha contra el gran fraude fiscal sino que se ha aprobado en 2013 una amnistía fiscal. Hay que tener presente que la caída del ingreso fiscal respecto

\footnotetext{
${ }^{15}$ Los investigadores de este tema sitúan el tipo efectivo del impuesto sobre el beneficio de las grandes empresas entre el 3,5\% y el 5\%. El de las PYMES, en cambio se sitúa por encima del $15 \%$.
} 
Oyarzun, Javier. La crisis del euro. Una reflexión sobre las políticas de austeridad y el diseño institucional de la Unión Económica y Monetaria Europea.

al PIB ha sido bastante superior en España que en la UE15 desde el principio de la crisis. La lucha contra el déficit se ha centrado en los gastos. Los mayores recortes del gasto se han producido en los gastos sociales (educación y sanidad) pero no en otros apartados que parecen más superfluos (instituciones poco operativas: diputaciones, senado; clientelismo: asesores de los políticos) y sobre todo que deben tener un carácter ejemplificador (sueldos y otros gastos de los políticos y empleados públicos, semipúblicos o privados de instituciones rescatadas). Por lo que respecta al ritmo de reducción del déficit, queda claro que la Comisión Europea ha hecho una programación deficiente de esta cuestión. Primero ha impuesto un ritmo de imposible cumplimiento y después lo ha relajado a la vista de la mala evolución de las economías de la zona.

Para el premio Nobel Paul Krugman (2015), la política de austeridad es considerada por los principales poderes políticos de la UEM, bajo la inspiración de Alemania, el justo castigo que merecen aquellos países que, como España, no han sabido ser comedidos y han derrochado en exceso.

Otra cuestión que debe ser tenida en cuenta es la responsabilidad de la deuda. Es claro que el prestatario es el principal responsable de la deuda contraída. Sin embargo, los prestamistas también tienen su parte de responsabilidad. Pues en el negocio del préstamo hay que ser muy prudente y no incurrir en riesgo de crédito, como ha ocurrido en el caso español. Obviamente, la institución supervisora del riesgo de crédito, el Banco de España, ha fracasado estrepitosamente, sin que haya habido asunción alguna de responsabilidades. Y, aunque el BCE no sea el supervisor, es indudable que tiene cierta responsabilidad al no adoptar ninguna medida ante el exceso de riesgo de crédito en que incurrieron muchos bancos y Cajas durante el boom inmobiliario en España. Sin embargo, en el discurso habitual, se obvia tanto la responsabilidad de las instituciones públicas como de las privadas.

La política monetaria adoptada por el BCE durante el periodo 2000-2008 también debe ser cuestionada. EI BCE ha explicado siempre que practica una política monetaria para el conjunto del área euro. La política de bajos tipos de interés era conveniente para reactivar la economía alemana, con escaso crecimiento, pero inadecuada para algunas economías periféricas donde la burbuja inmobiliaria iba inflándose. En el caso de España, acostumbrada a tener históricamente elevados tipos de interés, la política monetaria del BCE favoreció claramente el proceso de especulación en el mercado inmobiliario. La constatación de este hecho no resta, sin embargo, responsabilidad a las autoridades económicas españolas que no solo no frenaron la burbuja sino que toleraron la percepción de sueldos, indemnizaciones y jubilaciones astronómicas en las cajas de ahorro y algunos bancos.

b) Los desequilibrios macroeconómicos (excesivos déficit público y deuda pública y privada) "inquietan" a los mercados; la desconfianza de estos últimos se transmite a la prima de riesgo de las nuevas emisiones de deuda, lo que impide la recuperación de las economías "castigadas" por el encarecimiento de la deuda.

Otro de los argumentos a favor de la política de austeridad es que reducirá la prima de riesgo de los países con mayor déficit o deuda. Sin embargo, en 2010, 2011 y 2012 las políticas de austeridad no lograron ese resultado sino el contrario y las 
Oyarzun, Javier. La crisis del euro. Una reflexión sobre las políticas de austeridad y el diseño institucional de la Unión Económica y Monetaria Europea.

primas de riesgo fueron aumentando hasta alcanzar niveles insoportables en los países periféricos de la UEM (Grecia, Portugal, Irlanda, España e Italia). En la mayoría de estos países la deuda pública también siguió aumentando y el déficit se redujo moderadamente. Junto a la caída del gasto público se produjo la caída del ingreso fiscal debido a la caída de la producción y al aumento del paro; y el aumento de la prima incrementó el pago de intereses en la partida correspondiente del gasto público. Finalmente, en el verano de 2012 el gobierno español asumió la necesidad de solicitar el rescate para la banca (sobre todo para las Cajas) ${ }^{16}$, lo que unido a la prosecución de la recesión ha seguido alimentando el déficit y la deuda pública.

En realidad, la reducción de la prima de riesgo de los países periféricos se inició tras el mensaje lanzado por el gobernador del Banco Central Europeo (BCE), Mario Draghi, en el verano de 2012. Draghi anunció que el BCE intervendría en los mercados secundarios de deuda si los países afectados por altas primas de riesgo solicitaban apoyo al BCE (y cumplían las exigencias de este último). A partir de ese momento, los mercados se calmaron y las primas de riesgo iniciaron un descenso.

Este hecho es muy importante y significativo. Por varias razones. En primer lugar demuestra la falacia del argumento según el cual la reducción del déficit tiene una correlación a corto plazo con la reducción de la prima de riesgo. De hecho, los análisis econométricos no obtienen ese resultado. Y la razón es que el empeño en disminuir el déficit reduciendo fuertemente el gasto público conduce a una caída de la actividad y del ingreso público, con lo que el déficit apenas se reduce y la deuda pública sigue aumentando. El aumento de la deuda en situación de recesión sí tiene un efecto negativo en el mercado al aumentar el riesgo de impago del Estado. Por otro lado, el argumento no tiene en cuenta que el principal problema por el que la crisis ha golpeado duramente a España es el endeudamiento privado, derivado de la burbuja inmobiliaria y el apalancamiento de la banca, no el público. Y en el caso de Irlanda, donde deuda y déficit públicos también eran mucho menores que la media europea, el aumento del déficit y la deuda se debió a la quiebra del sistema financiero, sobredimensionado. En segundo lugar, revela que el aumento de la prima de riesgo deriva de la inexistencia de un verdadero Banco Central en la UEM. En efecto, el BCE carece de un atributo fundamental de los Bancos Centrales, el de prestamista de última instancia; es decir, la posibilidad de comprar deuda de los Estados miembros en el mercado primario o secundario ${ }^{17}$. Ante esta carencia, aumenta el temor de los mercados al impago de la deuda cuando esta aumenta en exceso. En tercer lugar, el diseño institucional de la UEM carece, tanto de mecanismos de supervisión de los desequilibrios fiscales como de mecanismos de rescate automático de los países miembros. Ante esta situación, como ha explicado De Grauwe (2011b, 2012), el mercado financiero de la UEM tiende hacia un equilibrio perverso en los países con elevados desequilibrios fiscales.

\footnotetext{
${ }^{16}$ Se acabó solicitando 40.000 millones de euros, aunque el crédito otorgado alcanza 100.000 millones de euros. Algunos analistas señalan que el gobierno español ha utilizado más de 40.000 millones del préstamo; sin embargo la información oficial no deja clara esta cuestión.

17 Aunque finalmente el BCE ha optado por asumir esa función de prestamista de última instancia. Primero en 2012, el mero aviso de que el BCE haría todo lo necesario para salvar la UEM bastó para que los mercados se calmaran y las primas de riesgo iniciaran su caída. Después, en 2015, siguiendo la política de la Reserva Federal se ha introducido la política de "quantitative easing", comprando deuda de los países de la UEM para inyecta liquidez en la economía.
} 
Oyarzun, Javier. La crisis del euro. Una reflexión sobre las políticas de austeridad y el diseño institucional de la Unión Económica y Monetaria Europea.

De Grauwe explica así el proceso. La secuencia empieza con el temor de algunos inversores al impago de la deuda pública por parte de un gobierno de la UEM Grecia u otro país periférico como España-. El temor al impago conduce a estos inversores a vender los bonos soberanos que detentan de ese país en el mercado secundario. El efecto de esa venta -cuando es suficientemente grande- es la reducción del valor de dichos bonos. Con ello aumenta el tipo de interés de los mismos: el bono vale menos pero el cupón es constante, lo que significa una mayor rentabilidad del bono. A continuación, con los euros obtenidos de la venta de los bonos, es probable que los inversores decidan comprar títulos más seguros, por ejemplo bonos alemanes. Esa operación, por un lado, detrae liquidez del país. Por otro lado, el gobierno del Estado emisor de los bonos cuyo tipo de interés ha aumentado, experimenta una crisis de liquidez: no puede obtener financiación barata -a bajo tipo de interés- para efectuar el pago de los intereses de los bonos emitidos.

A continuación De Grauwe explica que el fenómeno expuesto en el párrafo anterior no puede darse en países con soberanía monetaria -con moneda propia-. En efecto, en EEUU, Gran Bretaña o Japón, ese encarecimiento de la financiación no puede ocurrir -y no ha ocurrido de hecho durante la crisis- pues el Banco Central compraría toda la deuda que se emitiera al tipo establecido por el gobierno si el fenómeno expuesto se produjera.

La segunda parte de la secuencia conduce hacia una situación de agravamiento del problema; en ella la crisis de liquidez del gobierno se convierte en una crisis de solvencia, debida al aumento del tipo de interés. Este hecho no es sólo característico de las uniones monetarias, también lo es de los países en desarrollo que emiten bonos en divisas.

Este fenómeno es algo característico de los mercados financieros en determinadas circunstancias: propician las profecías que se autocumplen. Como en el caso de los pánicos bancarios (el temor a la quiebra de un banco, lo hace quebrar), el temor a la insolvencia de un gobierno lo hace insolvente. La venta de bonos -debida al temor de impago- aumenta el tipo de interés -el coste de financiación- y vuelve insolvente al gobierno. Resumiendo: las expectativas del mercado generan efectos que conducen al cumplimiento de dichas expectativas. Si las expectativas son buenas, el efecto es un equilibrio bueno; si son malas, el equilibrio que se establece es malo.

Para De Grauwe, los malos equilibrios en una unión monetaria tienen dos características que los hacen perversos. La primera es que vuelve muy vulnerables a los bancos. La desconfianza sobre la solvencia de un gobierno conduce a la venta de los bonos que ha emitido. Dichas ventas reducen el valor de los bonos (y aumentan su tasa de rentabilidad); como los bancos son los principales propietarios de los bonos, la reducción de su valor significa una reducción del valor de los activos de los bancos y, por lo tanto, una pérdida para ellos. Como en la UEM los mercados financieros están muy integrados y, en consecuencia, los bonos de los gobiernos están muy distribuidos entre los bancos de los países miembros, las malas expectativas sobre la solvencia de un gobierno pueden afectar a los bancos de muchos países de la unión monetaria. Es decir, el efecto contagio de las expectativas en una unión monetaria se convierte en una externalidad negativa de primer orden. La segunda característica es que en un equilibrio malo, los gobiernos no pueden emplear los estabilizadores automáticos. Como la recesión conduce a 
Oyarzun, Javier. La crisis del euro. Una reflexión sobre las políticas de austeridad y el diseño institucional de la Unión Económica y Monetaria Europea.

nuevos déficit fiscales y, en consecuencia, a un aumento de la deuda pública, los mercados empiezan a desconfiar de la capacidad de devolver la deuda y crean una crisis de liquidez (venta de bonos) que conducirá, en el supuesto de equilibrio malo, a una crisis de solvencia debido al aumento del tipo de interés de los bonos. Esta segunda característica es muy grave porque significa que, en una unión monetaria, algunos gobiernos pierden otro instrumento de ajuste macroeconómico de gran importancia para limitar los daños de una recesión, el aumento del gasto público.

La subida del tipo de interés de los bonos en el mercado secundario tiende a aumentar el tipo de las nuevas emisiones. Además interviene la calificación que las agencias de "rating" otorgan a la deuda soberana de los países. En el periodo de la crisis, las agencias han ido modificando las calificaciones de los bonos soberanos según la prima de riesgo que tenían. Es decir, las agencias han actuado de manera procíclica.

c) Las reformas estructurales asociadas a la política de austeridad permiten aumentar la competitividad internacional de los países en crisis a través de la reducción de salarios y precios. La mayor competitividad lograda por esta vía (que equivale a una devaluación del tipo de cambio) permitirá aumentar las exportaciones y reducir las importaciones, con lo que dará un impulso a la demanda externa e interna.

En los países donde la crisis coincidió en el tiempo con un fuerte déficit por cuenta corriente (casos de España e Irlanda), la solución clásica de la devaluación del tipo de cambio no era posible en una unión monetaria. En estos casos, y en otros también, la troika ha propuesto una opción alternativa, llamada devaluación interna.

La argumentación a través de la cual la devaluación interna iba a permitir, junto a las políticas señaladas más arriba, salir de la crisis gira en torno a la superación de la causa del déficit por cuenta corriente: la pérdida de competitividad de la economía. Para lograr este objetivo, la secuencia de acontecimientos que debía producirse era la siguiente (Uxó, 2014); en primer lugar, una reducción de salarios tanto en el sector público como en el privado. Para ello, era preciso realizar una reforma estructural en el mercado laboral ${ }^{18}$. La reducción salarial permitiría la reducción de los costes laborales unitarios (CLU), indicador macroeconómico de competitividad muy empleado por la economía ortodoxa. Con la mejora de la competitividad, aumentaría la demanda externa, es decir aumentarían las exportaciones de bienes y servicios y se reducirían -o crecerían menos- las importaciones. En la demanda interna se produciría una desviación del gasto, de las importaciones a los productos nacionales, ahora más competitivos. Como consecuencia de este proceso se superaría la crisis y llegaría la recuperación económica con la creación de empleo y el aumento paulatino de los salarios.

\footnotetext{
18 La reforma laboral se produce en España en 2012 y tiene como efecto, entre otros: 1) abarata considerablemente el despido; 2) facilita mucho la contratación temporal. El resultado de esta reforma ha sido aumentar el paro hasta más de seis millones en 2014 y aumentar las contrataciones temporales. En mayo de 2015, el número de parados es parecido al de finales de 2011, con una población activa muy inferior, y un fuerte aumento de los contratos temporales. Los salarios han bajado tanto en el sector público como en el privado. El nivel de desigualdad económica y de pobreza ha aumentado significativamente.
} 
Oyarzun, Javier. La crisis del euro. Una reflexión sobre las políticas de austeridad y el diseño institucional de la Unión Económica y Monetaria Europea.

Este relato ha tenido gran importancia en la argumentación de las instituciones que han dominado la dirección de la política económica en los países de la UEM durante la crisis. Esta argumentación, como las anteriores está muy sesgada por la ideología y los intereses que defiende; la analizaremos con detalle, contrastándola con la teoría y la realidad.

La primera observación se refiere a la utilización de los CLU agregados como indicador de la competitividad. Los CLU agregados no son un indicador adecuado de la competitividad de la economía de un país por varias razones. En primer lugar porque lo que se trata de determinar es la competitividad de las exportaciones y no del conjunto de la producción de bienes y servicios de un país. En ese sentido sería más correcto emplear los CLU de los productos exportados. Otro indicador de competitividad sería la cuota de la exportación de un país en el mundo; en el caso de España este indicador se ha mantenido estable en el periodo 2000-2007.

Finalmente, el aumento de los CLU puede deberse al aumento de los precios y no de los salarios (Estrada et al., 2013). Y esto es lo que parece haber sucedido en España pues los salarios han perdido peso en la renta nacional en favor de las rentas del capital. Es decir, lo que ha aumentado ha sido el beneficio de las empresas $^{19}$ (Álvarez, 2014). En definitiva, la utilización de los CLU agregados como indicador de competitividad es poco rigurosa; los datos de la exportación española en el periodo 2000-2007 son positivos pues mantiene su cuota en el mercado internacional en un periodo en que China gana cuota a la mayoría de los países desarrollados.

En segundo lugar, el análisis de la evolución de los CLU en la UEM toma como referencia el país donde estos han decrecido, Alemania. Es decir, en Alemania, la productividad ha aumentado más, en el periodo 2000-2008, que los salarios reales. Esta comparación no es acertada pues la regla de oro de la evolución de los CLU establece que los salarios reales deben aumentar igual que la productividad real, lo que daría lugar a un crecimiento equitativo de salarios y beneficios, no inflacionista ${ }^{20}$. Como veremos en el siguiente apartado, este tipo de análisis no es casual sino que responde a una determinada ideología sobre el funcionamiento que debe tener la UEM y se ha reflejado en el diseño institucional de la misma.

En tercer lugar, la política de devaluación interna consiste en una reducción de los salarios que, mediante su transmisión a los precios, debería aumentar la demanda externa. A este respecto hay que hacer dos comentarios. Primero, la reducción salarial, como se ha visto en España y otros países, reduce la demanda interna, de manera que el aumento de la demanda externa tiene que compensar, al menos, la reducción de aquella; esto no ha ocurrido en España porque la exportación española tiene una intensidad tecnológica muy alejada de aquellos países, como Alemania y Japón, cuyo crecimiento está impulsado por las exportaciones. La oferta de

\footnotetext{
19 La política de austeridad aplicada en España entre mayo de 2010 y 2015 ha producido una reducción significativa de los CLU; sin embargo, los precios no se han reducido porque el aumento de la productividad por encima del salario se ha transmitido a un aumento de los beneficios.

${ }^{20}$ Numerosos economistas y políticos modifican esa regla de oro, igualando el aumento del salario nominal con el de la productividad real (Estrada et al.). Es decir, proponiendo un menor crecimiento de los salarios que de los beneficios. Es lo que ha hecho Alemania, aplicando lo que algunos autores denominan una política "neomercantilista".
} 
Oyarzun, Javier. La crisis del euro. Una reflexión sobre las políticas de austeridad y el diseño institucional de la Unión Económica y Monetaria Europea.

exportación española es, en su mayoría, de intensidad tecnológica media y baja y la elasticidad-precio de su demanda es relativamente baja; por ello, es una quimera pensar que España, como Alemania, puede -a corto o medio plazo- basar su modelo de crecimiento en la exportación. Segundo, la contracción simultánea de la demanda en todos los países de la UEM provoca un callejón sin salida: si todos los países ganan competitividad pero todas las demandas caen, ¿donde encontrarán comprador estos países aunque aumenten su competitividad ${ }^{21}$. En definitiva, la aplicación generalizada de las políticas de austeridad en todos los países con déficit fiscal es absurda (Wolf, 2013). Esta última reflexión pone de relieve uno de los mayores defectos del diseño institucional de la UEM, que analizaremos en el siguiente apartado.

En cuarto lugar, el creciente déficit por cuenta corriente de la economía española en el periodo 2000-2008 tuvo su origen en el fuerte crecimiento económico del periodo, impulsado por la burbuja inmobiliaria y financiado por las economías superavitarias de Europa central, en particular Alemania. Es decir, el superávit por cuenta corriente de Alemania tuvo como contrapartida, por un lado, el déficit corriente de España y, por otro, la financiación del mismo por el superávit alemán. Este hecho revela la complementariedad entre ambos desequilibrios: el déficit español se debe, en parte, al superávit alemán y viceversa.

En quinto lugar, varios investigadores (Estrada et. al., 2013, Uxó, 2014) señalan que las economías de la UEM y, en particular, la española son economías impulsadas por los salarios (wage-led), no por los beneficios (profit-led). Por lo tanto, la reducción salarial no es una estrategia adecuada para crecer lo suficiente e ir reduciendo el endeudamiento -privado y público- y recuperando los niveles de renta y bienestar perdidos.

En sexto lugar, la economía española debería apostar por un aumento de su productividad y no por una reducción de su nivel de bienestar, que es de los más bajos de la UEM. Este es el objetivo que los economistas españoles han venido reclamando desde hace décadas. No debemos acercarnos al modelo de China sino al modelo del norte de Europa. Y el aumento de la productividad en España pasa por una profunda reforma de las instituciones, una mayor inversión en I+D y una mayor inversión en capital fijo. Sin embargo, la reducción de los salarios desincentiva la inversión en capital y las mejoras tecnológicas puesto que aumenta el coste de oportunidad de la sustitución de trabajo por capital.

En séptimo lugar, la reducción de los salarios y de la inflación, rozando el fantasma de la deflación en muchos países europeos, es una mala estrategia para la resolución del problema de la deuda. Como señaló en los años treinta Irving Fisher, la "deflación de deuda" es uno de los peores enemigos de la recuperación. Si el nivel de precios baja -si hay deflación-, la deuda, en términos reales sube. Esa situación pondría la economía española al borde del impago y la restructuración de la deuda sería inevitable. Afortunadamente, el BCE ha reaccionado con una fuerte inyección de liquidez a través de la compra de deuda pública de los países de la UEM con el fin de evitar la deflación y reactivar la economía.

\footnotetext{
${ }^{21}$ Podrían encontrarlo en el mercado extra UEM, en cuyo caso trasladarían el problema a estos países.
} 
Oyarzun, Javier. La crisis del euro. Una reflexión sobre las políticas de austeridad y el diseño institucional de la Unión Económica y Monetaria Europea.

\section{LA DISFUNCIONALIDAD DEL SISTEMA MONETARIO DE LA UEM}

Como se indicaba en el segundo apartado, el tratado de Maastricht se enmarca en un periodo de predominio creciente del pensamiento neoliberal, en el que tienen lugar un conjunto de cambios en la política y la regulación económicas; entre los primeros hay que destacar un mayor énfasis en los equilibrios macroeconómicos, sobre todo el fiscal, y la estabilidad de precios. Entre los segundos, la liberalización de todos los mercados -bienes, servicios y factores-, su desregulación parcial -caso del sector financiero-, la privatización de las empresas públicas, la apertura comercial y de los movimientos internacionales del capital. Esta ideología está presente en el tratado de Maastricht y en el diseño institucional de la UEM y es, en parte, responsable de sus disfuncionalidades (Krugman, 2014).

En primer lugar, el diseño de la UEM es muy rígido. Deja un margen de maniobra muy escaso a los gobiernos. El cumplimiento del Pacto de Estabilidad y Crecimiento $\left(\mathrm{PEC}^{22}\right.$ ) y las características de la política monetaria en la zona euro son las bases sobre las que actúan los órganos de gobierno de la UEM, el eurogrupo y el BCE. El PEC supone un corsé con el que se justifica la imposición de las políticas económicas a los países del euro. La combinación de una política monetaria con un margen de actuación limitado ${ }^{23}$ y unos límites estrictos al déficit público de los países miembros, ha demostrado, en los 7 años de crisis transcurridos, su escasa eficacia y la asimetría de sus reglas.

La política monetaria está dirigida por el BCE, que tiene independencia respecto a los restantes órganos de la UEM. Debe atenerse al mandato que establece el Tratado de Maastricht consistente en mantener un bajo nivel de inflación. Es el único mandato explícito; aunque no se dan cifras concretas, parece establecido que la tasa de inflación del conjunto de la zona euro debe situarse por debajo del $2 \%$ pero muy próximo a este valor. Sin embargo, esa meta es puramente convencional y resulta demasiado baja en las condiciones cercanas a la deflación por las que pasan muchos países de la UEM (Alvarez et. al, 2013).

En segundo lugar, la ausencia de un mandato al BCE sobre la utilización de la política monetaria para influir sobre el crecimiento es otra limitación del diseño de la UEM. Si bien el BCE, a partir del mandato de Draghi ha realizado actuaciones de inyección masiva de liquidez, el destino de estas actuaciones ha estado más dirigido a sanear las cuentas de los bancos y dar salida a las emisiones de deuda de algunos estados que a promover el crecimiento en la zona. Es lo que sucedió en 2012, cuando se proporcionó a la banca europea préstamos cercanos al billón de euros a un tipo de interés del $0,5 \%$. En aquella circunstancia la banca española dedicó buena parte de esos fondos a comprar deuda pública del gobierno español a un tipo de interés que, en aquellos momentos superaba el 6\%. Es decir, la banca privada intermediaba fondos del BCE hacia el sector público español obteniendo una ganancia superior al $5 \%$, con escaso riesgo. Este ejemplo pone de relieve un aspecto relevante de la conducta del BCE y de su política monetaria. EI BCE apoya prioritariamente a la banca, en el doble papel que esta última ejerce como prestamista y como prestataria.

\footnotetext{
${ }^{22}$ El PEC fue aprobado en el Tratado de Amsterdam, en junio de 1997.

${ }^{23}$ Aunque ha aumentado desde mediados de 2012 como ya hemos señalado.
} 
Oyarzun, Javier. La crisis del euro. Una reflexión sobre las políticas de austeridad y el diseño institucional de la Unión Económica y Monetaria Europea.

La conducta del BCE con la banca, expuesta en el párrafo anterior, es sintomática del carácter asimétrico de la política económica que impulsa la troika, que sería la tercera disfuncionalidad de la organización de la UEM. Desde que se impuso la política de austeridad en mayo de 2010, los ajustes impuestos a los países de la UEM han favorecido a todos los acreedores, sean países (los que tienen superávit por cuenta corriente) o sean agentes económicos (los bancos) frente a los países (los que tienen déficit por cuenta corriente) y los agentes deudores. Para los primeros no ha habido ninguna exigencia de ajuste, todos los ajustes han recaído en los segundos. Sin embargo, como señalábamos en el apartado anterior, una política que pretenda favorecer al conjunto de las economías de la zona euro debería ser más simétrica. Es decir, imponer ajustes tanto a los acreedores como a los deudores. A nivel macro, la razón es clara: el déficit por cuenta corriente de unos países requiere el superávit corriente de otros. En un sistema con moneda única, al igual que se exige a los países con déficit que bajen salarios y precios, se debería exigir a los países con superávit que hagan lo contrario: subir salarios y precios. Esta es la simetría que debería producirse para que hubiera un necesario nivel de solidaridad entre los países de la UEM. Porque si bien se resalta que algunos países han vivido por encima de sus posibilidades se obvia la contrapartida necesaria para que aquello sea posible: que otros han vivido por debajo de las suyas. En efecto, esta exigencia de simetría sería equitativa y positiva para todos los países de la zona euro. La subida de salarios y precios en los países acreedores reduciría su competitividad y aumentaría su demanda de importaciones; en los países con déficit, aumentarían las exportaciones a los anteriores países y se corregiría su déficit sin generar paro (Krugman, 2012). En los países con superávit mejoraría el nivel de bienestar de sus trabajadores. Sería una política más coherente, justa y provechosa para el conjunto del área. No hay que olvidar que una unión de países (o de cualquier otro colectivo) no puede funcionar solamente con principios de competencia; son también necesarios los principios de cooperación.

Muy vinculado a la disfuncionalidad que acabamos de señalar, se encuentra otra que es, en buena medida, la que ha dado lugar a la asimetría de la evolución de las economías del centro, por un lado, y de la periferia, por otro. Este fallo del diseño institucional nace de las limitaciones inherentes a un espacio económico con instrumentos económicos comunes e instrumentos integrados solo parcialmente (la política fiscal, de balanza de pagos). La adopción del euro y la estricta política antinflacionista del BCE se tradujeron en un tipo de interés muy reducido en la zona euro, con escasos diferenciales entre países debidos a la prima de riesgo. Esta igualación del tipo de interés en toda la zona euro no fue positiva para el futuro económico de un grupo de países, entre ellos España y, seguramente, Alemania. Porque, en el caso de España, el bajo tipo de interés que se establece desde el año 2000 va a incentivar la aparición y el desarrollo de una burbuja inmobiliaria (y bursátil) muy intensa. La expansión de la burbuja fue alimentada por una burbuja de crédito procedente, en gran parte, de los países de la UEM con superávit por cuenta corriente (sobre todo, Alemania). Es decir, en el caso de España, el aumento de la demanda interna impulsado por la burbuja inmobiliaria se tuvo que satisfacer, en parte, con un aumento de las importaciones, lo que, por un lado, se tradujo en un creciente déficit por cuenta corriente $y$, por otro, proporcionó la financiación necesaria para seguir alimentando la burbuja, procedente de los países origen de dichas importaciones (Álvarez et al., 2013). La experiencia contrapuesta registrada 
Oyarzun, Javier. La crisis del euro. Una reflexión sobre las políticas de austeridad y el diseño institucional de la Unión Económica y Monetaria Europea.

en España y Alemania revela que, dada la igualación del tipo de interés en todos los países de la zona euro, el eurogrupo debió tomar medidas para controlar el riesgo de crédito, los déficits por cuenta corriente y la evolución de las burbujas y actuar para frenar el crecimiento de los mismos.

En quinto lugar hay que señalar que, inicialmente, la UEM no contaba con mecanismos de intervención automáticos en caso de crisis. De hecho, el efecto que tuvo sobre el conjunto de la UEM el descubrimiento de la situación real de las cuentas públicas de Grecia, a finales de 2009, es un síntoma inequívoco de un mal diseño de la eurozona. El hecho de que el verdadero déficit público de Grecia, un país cuyo PIB representa el $3 \%$ del PIB de la eurozona, hubiera sido ocultado durante varios años a las autoridades de la UEM, no debería haber tenido el impacto en la eurozona que tuvo. Por un lado, habría tenido que existir un sistema de supervisión eficiente de las cuentas públicas de los países de la UEM; por otro, una vez descubierto el fraude, las instituciones de la UEM deberían haber actuado de manera urgente y efectiva para detener el pánico que cundió entre los inversores. Nada de eso se hizo y la situación de una economía muy pequeña de la eurozona generó un daño considerable a la estabilidad y a la economía de muchos países de la UEM. Uno se pregunta ahora, ¿por qué no se actuó entonces -a principios de 2010- como se hizo dos años más tarde, inyectando liquidez de manera masiva para frenar la subida de las primas de riesgo de algunos países? La ausencia de todos esos mecanismos de control e intervención en los mercados es la que ha propiciado la subida imparable de las primas de riesgo, el pánico de los mercados y el enorme daño causado a muchas economías periféricas de la UEM. Se ha vuelto evidente que los mercados financieros deben estar bien regulados y supervisados en una unión monetaria.

En sexto lugar, una unión monetaria sin unión fiscal es un sistema cojo. Las advertencias de algunos economistas, sobre todo de EEUU, sobre esta carencia de la UEM eran razonables. En la UEM no solo no hay unión fiscal, es decir una fiscalidad común, como ocurre en los Estados soberanos, no hay siquiera homogeneidad en los impuestos directos. En los impuestos indirectos hay cierto grado de homogeneidad (hay tramos de IVA similares pero los tipos difieren) pero en los impuestos directos no ha habido nunca acuerdo porque en el Acta Única Europea se aprobó que las decisiones en materia fiscal se adoptaran por unanimidad en el Consejo Europeo. Esa decisión debió sustituirse cuando se aprobó el Tratado de Maastricht pues la diversidad impositiva en el impuesto de sociedades, por ejemplo, da lugar a una competencia desleal de algunos países, que bajan dicho impuesto para atraer inversiones. Más recientemente hemos tenido conocimiento de otros países o territorios de la UEM que son también, en realidad, paraísos fiscales $^{24}$. En consecuencia, es preciso lograr una convergencia en la imposición directa de forma previa a la unión fiscal.

Finalmente, el sistema institucional de la UEM, como lo es la propia UE, es escasamente democrático. Después de todo lo ocurrido, ninguna institución de la UEM aparece como responsable de la mala gestión de la crisis. El déficit democrático de la UE se ha reproducido, con más intensidad, en la UEM. Si el parlamento de la UE es poco operativo, en la UEM ni siquiera existe. Tras los años

\footnotetext{
${ }^{24}$ Se mencionan sobre todo: Irlanda (con un impuesto de sociedades del 12\%), Luxemburgo, Austria, Chipre.
} 
Oyarzun, Javier. La crisis del euro. Una reflexión sobre las políticas de austeridad y el diseño institucional de la Unión Económica y Monetaria Europea.

transcurridos desde el inicio de la crisis la desafección de la sociedad europea con la UE es creciente. Para fortalecer la UEM, y la UE, deben introducirse profundas reformas democráticas en el sistema institucional. Algunos grupos socialdemócratas han propuesto introducir en la UEM un conjunto de instituciones comunes (Fundación Friedrich-Ebert-Stiftung, 2014): a) un seguro de desempleo; b) un parlamento; c) un impuesto de sociedades común; d) un impuesto sobre emisión de $\mathrm{CO}^{2}$; e) un impuesto sobre transacciones financieras; f) mancomunar parte de la deuda pública (por encima del $60 \%{ }^{25}$ ). Iniciativas de este tipo permitirían recuperar algo de ilusión por un proyecto que se ha ensombrecido.

\section{CONCLUSIONES}

La crisis en la UEM ha sido más intensa que en los restantes países de la OCDE. Las razones por las que esto ha sucedido derivan del hecho que es una unión monetaria mal diseñada y cuyas políticas han defendido de forma asimétrica los intereses de los países miembros de la zona.

El diseño de la UEM se construyó en un momento histórico, el segundo quinquenio de la década de 1980, cuando la Unión Europea estaba en proceso de convertirse en un Mercado Único en 1992. Fueron los años de pujanza del pensamiento y las políticas neoliberales en la mayor parte del mundo. El tratado de Maastricht está impregnado de esta ideología y, además, está diseñado por Alemania, que no estaba interesada en crear la unión monetaria. En consecuencia, Alemania, para aceptar entrar en el proyecto del euro, impuso las condiciones que estimaba más convenientes. Estas condiciones fueron los criterios de convergencia para entrar en la UEM y el PEC, que consiste en hacer permanentes los criterios fiscales (déficit máximo del $3 \%$ del PIB y deuda máxima del $60 \%$ del PIB). Pese a las muy posibles implicaciones negativas del diseño acordado para la UEM, los gobiernos de los países que finalmente formaron la unión eran muy optimistas y fueron escasas las voces críticas en Europa sobre el tratado de Maastricht. El discurso más extendido era que la creación de la unión monetaria produciría avances en la integración política de la UE.

El diseño resultante de la UEM tenía numerosas carencias que se reflejaron durante el periodo 2000-2007 y, después, durante el transcurso de la crisis. En la fase de la UEM previa a la crisis, se estableció un tipo de interés demasiado bajo para los países periféricos y demasiado alto para los países centrales. Esta diferencia entre las necesidades de uno y otro grupo generó divergencia en el crecimiento de ambos grupos. En España, el bajo tipo de interés impulsó una burbuja inmobiliaria y bursátil, que generó un fuerte crecimiento y un déficit por cuenta corriente muy elevado. En Alemania, polo opuesto en resultados, la reforma laboral de inicios de la década de 2000 frenó el crecimiento salarial y la demanda interna. La economía alemana se sostuvo gracias a la potente demanda externa, procedente, entre otros, de los países periféricos, que produjo fuertes superávit por cuenta corriente; sin embargo, la atonía de la demanda interna dio lugar a un crecimiento muy bajo del PIB. Cuando, como consecuencia del estallido de la crisis, se seca la financiación, aquellos países, como España, cuya economía estaba alimentada por el endeudamiento, colapsan. Entonces, los estabilizadores automáticos originan un

\footnotetext{
${ }^{25}$ Es una idea que fue propuesta por De Grauwe (2011a).
} 
Oyarzun, Javier. La crisis del euro. Una reflexión sobre las políticas de austeridad y el diseño institucional de la Unión Económica y Monetaria Europea.

fuerte déficit fiscal en aquellos países donde estalla la burbuja y la demanda cae bruscamente al detenerse la financiación.

Tras una respuesta tímidamente keynesiana en 2009, la revelación del verdadero déficit de Grecia y su posterior rescate modificaron drásticamente la política del eurogrupo, bajo la inspiración de Alemania. Se impuso la vuelta a los equilibrios fiscales y la aplicación de una política de austeridad para alcanzarlos. Este trabajo ha abordado el análisis de tres argumentos muy difundidos por políticos y economistas favorables a la política de austeridad. En general, son argumentos que analizan parcialmente el problema, le aplican la receta de austeridad a esa parte y le atribuyen efectos beneficiosos para el conjunto. Son falacias de composición. Como señala Krugman (2015) se vende la idea de una "austeridad expansiva" cuando en realidad ese pensamiento representa un regreso al prekeynesianismo, una recuperación de la ley de Say.

Sin embargo la política de austeridad no era la única posible, como se ha visto en EEUU, por ejemplo. En España y otros países periféricos, esta política ha sido destructiva pues ha empobrecido intensamente a la mayoría de la población y ha mermado significativamente el estado de bienestar, además de aumentar la deuda pública. Los principales beneficiarios han sido los acreedores extranjeros, los bancos nacionales y las grandes empresas. En España, el paro se ha situado cerca del $25 \%$ y la precariedad y temporalidad en los nuevos contratos laborales se ha vuelto lo más habitual ${ }^{26}$.

En el marco de la UEM, las políticas alternativas deben incorporar una mayor simetría en su diseño y aplicación. La austeridad para todos no puede funcionar. Los países acreedores deben aumentar su demanda interna y, para ello, facilitar un aumento de los salarios que permita recuperar la participación de estos últimos en la renta. El aumento de la demanda interna de estos países tendrá un doble efecto beneficioso para la economía de la zona. Por un lado, aumentará las exportaciones de los países periféricos, lo que generará crecimiento y aumentará el equilibrio externo en estos países; por otro, permitirá un ligero aumento de la inflación, lo que aliviará el coste de la deuda de los países donde ha alcanzado un nivel insostenible, al reducirla en términos reales. Como indican Reinhardt y Rogoff (2012), el aumento deliberado de la inflación ha sido una de las principales estrategias adoptadas por los países a lo largo de la historia para reducir la deuda (pública y privada). El sector financiero ha sido el que ha recibido mejor trato por parte de los gobiernos de la UEM (rescates, avales, préstamos a tipos preferenciales, nacionalizaciones); es el momento de que realicen su contribución a la solución de una crisis en cuya gestación han tenido gran responsabilidad.

Otras reformas necesarias para mejorar el funcionamiento de la UEM son de mayor calado. Una unión monetaria sin integración fiscal es disfuncional. El avance en la integración fiscal es preciso para devolver credibilidad al proyecto europeo. Se podría empezar por la convergencia del sistema impositivo directo y la represión del fraude fiscal en la UEM. A partir de ahí, se podría plantear la integración fiscal. Y una profundización en la gobernanza democrática de la Unión Europea.

\footnotetext{
${ }^{26}$ La información sobre el paro registrado en España en el mes de mayo de 2015 revela que el $93 \%$ de los nuevos contratos firmados en mayo son o bien temporales o a tiempo parcial.
} 
Oyarzun, Javier. La crisis del euro. Una reflexión sobre las políticas de austeridad y el diseño institucional de la Unión Económica y Monetaria Europea.

La UEM se encuentra en una encrucijada para su futuro como organización política y económica. Hasta ahora ha fracasado como proyecto de integración. Más bien ha supuesto una desintegración parcial en tanto que la cohesión de los Estados en el proyecto común se ha debilitado fuertemente. Sin embargo el coste de la ruptura del euro es muy elevado. Lo es su desaparición como institución y también lo es si hay una ruptura parcial. Esta segunda opción parece la única posible puesto que el BCE ha actuado de forma muy enérgica para evitar la muerte de la institución y, por lo tanto, la suya propia. La ruptura parcial, sin embargo, supondría la constatación de un fracaso y un mayor cuestionamiento del sistema.

A pesar de la dificultad para salir del callejón en que se encuentra la UEM, algunos acontecimientos pueden abrir una puerta a la esperanza. El BCE actuó en 2012 con decisión para evitar la escalada de las primas de riesgo y el hundimiento subsiguiente de la zona euro. Más tarde, a finales de 2014, el BCE emprendió una masiva inyección de liquidez mediante el programa de compras de deuda pública de los países de la UEM. El objetivo era doble: por un lado evitar la temida deflación; por otro estimular la concesión de crédito al aumentar la liquidez bancaria. A estos acontecimientos se han venido a añadir la depreciación del euro y la caída del precio del petróleo. Nos encontramos por lo tanto en un punto de inflexión que habría que aprovechar para seguir la construcción del proyecto de la UEM con una visión más cooperativa, simétrica y democrática. 
Oyarzun, Javier. La crisis del euro. Una reflexión sobre las políticas de austeridad y el diseño institucional de la Unión Económica y Monetaria Europea.

\section{BIBLIOGRAFÍA}

Álvarez, Ignacio (2014): "La recuperación económica impulsada por los salarios: una alternativa a la deflación." Diario digital Infolibre, 8/4/2014.

Álvarez, Ignacio; Luengo, Fernando; Uxó, Jorge (2013): Fracturas y crisis en Europa. Ed. Eudeba, Buenos Aires y Ed. Clave Intelectual, Madrid.

Commission des Communautés européennes (1990): Marché unique, monnaie unique. Une évaluation des avantages et coûts potentiels de la creation d'une union économique et monétaire. Économie Européenne, no 55, octubre 1990.

Estrada, Bruno; Paz, María José; Sanabria, Antonio (2013); Uxó, Jorge: Qué hacemos con la falacia que vincula la salida de la crisis con bajadas salariales que en verdad no mejoran la competitividad. Ed. Akal, Tres Cantos, 2013.

De Grauwe, Paul (2012): "Lessons from the Eurocrisis for East Asian Monetary Relations", The World Economy, 2012.

http://www.econ.kuleuven.be/ew/academic/intecon/Degrauwe/PDG-

Publications_recent.htm\#discussion papers

De Grauwe, Paul (2011a): "La crisis de la deuda soberana y el futuro del euro". Claves de la Economía Mundial, Madrid 2011.

De Grauwe, Paul (2011b): "Managing a Fragile Eurozone". Focus, 2011. http://www.econ.kuleuven.be/ew/academic/intecon/Degrauwe/PDG-

Publications_recent.htm\#discussion papers

De Grauwe, Paul (1992): Teoría de la Integración Monetaria. Hacia la Unión Monetaria Europea. Celeste Ediciones, Colegio de Economistas de Madrid, Madrid 1994.

Feldstein, Martin (2011): The Euro and European Economic Conditions. Working Paper 17617, NBER, nov. 2011.

Fundación Friedrich-Ebert-Stiftung (2014): III Informe sobre el estado de la Unión Europea. La ciudadanía en tiempo de crisis. Friedrich-Ebert-Stiftung http://www.exlibrisediciones.com/alternativas/estadoue.swf

Kindleberger, Charles., Aliber, R. (2011): Manías, pánicos y cracs: historia de las crisis financieras. Ed. Ariel Economía, Madrid 2012.

Krugman, Paul (2015): "That Old-Time Economics", New York Times, 17/4/2015.

Krugman, Paul (2014): "Why Weren't Alarm Bells Ringing?". New York Review of Books, 23/10/2014.

Krugman, Paul (2012): "El suicidio económico de Europa”. El País, 22/4/2012.

Krugman, Paul (2010): “¿Por qué seguimos cayendo?. El País, 3/10/2010.

Mundell, Robert (1961): "A Theory of Optimal Currency Areas”, American Economic Review. 51.

Reinhart, Carmen, Rogoff, Kenneth (2012): Financial and Sovereign Debt Crises: Some Lessons Learned and Those Forgotten. Documento presentado por los autores para la conferencia del FMI (14/9/2012): "Financial Crisis: Causes, Consequences, and Policy Responses".

Uxó, Jorge (2014): El mito de la flexibilidad salarial y el ajuste en la unión monetaria. La devaluación interna en España. Ponencia presentada en el seminario de investigación de la FCCEE de la UCM en 2014, publicada en youtube el 22/1/2015. https://www.youtube.com/watch?v=vu7y7YQ3EGo

Vilariño, Ángel (2009): "Formación de burbujas financieras y crisis: de la crisis del NASDAQ a la crisis de las hipotecas subprime", Papeles de Europa, 19 (2009). 
Oyarzun, Javier. La crisis del euro. Una reflexión sobre las políticas de austeridad y el diseño institucional de la Unión Económica y Monetaria Europea.

Vilariño, Ángel, Alonso, Nuria, Trillo, David (2011a): "La falacia del Spread de la deuda soberana como indicador de la solvencia del Estado. Ponencia presentada en la XIII Reunión de Economía Mundial, mayo de 2011.

Vilariño, Ángel (2011b): "La crisis financiera: orígenes y desencadenantes", en Economía política de la crisis (coord.. Pedro J. Gómez Serrano), Editorial Complutense, Madrid 2011.

Wolf, Martin (2013): "How Austerity Has Failed”, The New York Review of Books, 11 de julio de 2013. 